\title{
The Deterioration Mechanism of Diester Aero Lubricating Oil at High Temperature
}

\author{
Ting Yao, ${ }^{1,2}$ Hongwei Yang, ${ }^{3}$ Li Guo, ${ }^{3}$ Yiwei Fei, ${ }^{3}$ Huize Jiang, ${ }^{3}$ Sen Bian, ${ }^{3}$ and Tonghai $\mathrm{Wu}^{2}$ \\ ${ }^{1}$ Analysis and Testing Center, Huangshan University, Huangshan, Anhui 245041, China \\ ${ }^{2}$ Key Laboratory of Education Ministry for Modern Design and Rotor-Bearing System, School of Mechanical Engineering, \\ Xi'an Jiaotong University, Xi'an 710049, China \\ ${ }^{3}$ Department of Aero Oil and Material, Air Force Logistics College, Xuzhou, Jiangsu 221000, China
}

Correspondence should be addressed to Ting Yao; ttyaoting@163.com

Received 29 June 2017; Accepted 21 August 2017; Published 31 October 2017

Academic Editor: Xing Fan

Copyright (C) 2017 Ting Yao et al. This is an open access article distributed under the Creative Commons Attribution License, which permits unrestricted use, distribution, and reproduction in any medium, provided the original work is properly cited.

\begin{abstract}
The deterioration of aero lubricating oil at high temperatures was accelerated by using a specific device simulating the operating conditions of engines, where the deterioration mechanism was obtained. Structures of the deteriorated lubricating oils were analyzed by gas chromatograph/mass spectrometer. From the results, it can be concluded that deterioration of aero lubricating oil at high temperatures was composed of thermal pyrolysis, oxidation, and polymerization, with the generation of a variety of products, such as alcohols, aldehydes, acids, and esters, which caused the deterioration of physicochemical properties of the aero lubricating oil.
\end{abstract}

\section{Introduction}

The change of molecular structure of aero lubricating oil is the fundamental cause that affects the functions of oil at high temperature [1-5]. The deterioration process, which includes thermal pyrolysis, oxidation, and polymerization, is complicated. The identification of products and investigation of reaction process can effectively explain the cause of deterioration mechanism of aero lubricating oil at high temperature, which can provide the theoretical basis for developing new and high-end lubricating oils.

The tested aero lubricating oil is a kind of synthetic lubricating oil with diisooctyl sebacate (DIOS) as its based oil, which has been extensively used in a certain type of aircraft engine lubrication system. The lubricating properties of aero lubricating oil will change due to deterioration caused by high temperature, high pressure, and high shearing, along with metallic catalysis (i.e., copper and iron) under the conditions of being exposed to the air. The deteriorated oil will do harm to the functions of the engine afterwards $[6,7]$. In recent years, the deterioration of diester lubricating oil was focused on the performance deteriorated at high temperatures
[8-11]. Chen et al. explored the change about antioxidants during the decay of some aero lubricating oil. It was found that thermal oxidation of antioxidant was a pseudo-firstorder reaction and the equation of reaction kinetics was obtained [8]. Fei et al. analyzed the pyroreaction products of diisooctyl adipate of aero lubricating oil using gas chromatograph/mass spectrometer (GC/MS) and indicated that the formation of substances (i.e., ketones, ethers, alcohols, and acids) was the primary cause of color deepening and increase of acid number [9]. Wu et al. simulated the oxidation of DIOS to investigate the lubricating properties of oil products under different degrees of oxidation by a four ball tester. The results showed that the formation of peroxide during the oxidation process of lubricating oil led to the deterioration of lubricating properties of oil products and occurrence of some polar products decreased abrasion loss [10]. Santos et al. analyzed the product of thermal deterioration by using FTIR and GC/MS, who found that the structure change was related with property change [11]. In these studies, the effect of factors and property changes of diester-like lubricating oil were focused on thermal oxidation. However, few studies concern the process and mechanism of thermal deterioration. 
In the present investigation, some aero lubricating oil was subjected to simulating its oxidation under different high temperatures using the simulative device and subsequently analyzed by GC/MS. The deterioration mechanism was focused on investigation. This is of a great significance in improving the high-temperature performance of an aero lubricating oil, determining the appropriate oil change intervals and realizing the long-term quality monitoring on aero lubricating oil.

\section{Experimental Section}

2.1. Materials. Some aero lubricating oil was collected from some Fuel Research Institute. The reagents used in the experiment are analytical ones which are commercially available. All reagents (petroleum ether, $n$-hexane, acetone, and so on) used in the experiments were analytical reagents, and all the organic solvents had been distilled before use.

\subsection{Simulation Testing on High-Temperature Oxidation.} $128 \mathrm{~g}$ aero lubricating oil was added into a device $(500 \mathrm{~mL}$ volume, $32 \mathrm{MPa}, 450^{\circ} \mathrm{C}, 1100 \mathrm{r} / \mathrm{min}$, and $2 \mathrm{~kW}$, SongLing Co. Ltd, Yantai, China) simulating the operating conditions of the engine. The experimental lubricating oils were heated to the required temperatures $(180,200,230,250,270$, and $300^{\circ} \mathrm{C}$ ) for $2 \mathrm{~h}$, respectively, and the stirring rate was $800 \mathrm{r} / \mathrm{min}$. For the convenience of description, the six experimental oils were marked with $\mathrm{EO}_{180}, \mathrm{EO}_{200}, \mathrm{EO}_{230}$, $\mathrm{EO}_{250}, \mathrm{EO}_{270}$, and $\mathrm{EO}_{300}$, respectively. After the reaction, the device was immediately placed in ice water until room temperature. The experimental oils were filtered and kept in dark conditions.

2.3. Acid Value Testing. The determination of acid values in testing samples is made in accordance with GB/T 264-1983(1991) Standard Testing Methods.

2.4. GC/MS Analyses. Oil samples were analyzed with a Hewlett-Packard 6890/5973 GC/MS, which was equipped with a capillary column coated with HP-5MS (cross-link 0.5\% PH ME siloxane, $60 \mathrm{~m}$ length, $0.25 \mathrm{~mm}$ inner diameter, $0.25 \mu \mathrm{m}$ film thickness) and a quadrupole analyzer with an $\mathrm{m} / \mathrm{z}$ range from 33 to 500 and operated in electron impact $(70 \mathrm{eV})$ mode. The capillary column was heated from 120 to $274^{\circ} \mathrm{C}$ at a rate of $13^{\circ} \mathrm{C} \mathrm{min}^{-1}$ and held for $2 \mathrm{~min}$, then raised to $281^{\circ} \mathrm{C}$ at a rate of $0.5^{\circ} \mathrm{C}$ and held for $2 \mathrm{~min}$, finally raised to $300^{\circ} \mathrm{C}$ at a rate of $12^{\circ} \mathrm{C}$ and held at $300^{\circ} \mathrm{C}$ for $3 \mathrm{~min}$. Data were acquired and processed using software of Agilent MSD Productivity Chemstation. Compounds were identified by comparing mass spectra with NIST05a library data.

\section{Results and Discussion}

3.1. Color and Molecular Compositions of Oils. As a direct appearance index, color change of oils can be determined by various factors, including both internal ones (base oil, additive, oil pigment, and so forth) and external conditions (temperature, high pressure, high shearing, metal catalysis, oxidation, run time, and so forth) [12]. In this study, color of oils in different high-temperature reactions became more noticeable. $\mathrm{EO}_{180}$ is almost pale yellow and transparent at $180^{\circ} \mathrm{C}$. As the reaction temperature rose, the color gradually deepens. It is worth noting that color becomes most remarkable at $230^{\circ} \mathrm{C}$, even looking reddish brown. $\mathrm{EO}_{300}$ became not transparent but showed deep chocolate brown at $300^{\circ} \mathrm{C}$. Most of aero lubricating oils were undergone significant color change under the high temperature, which provided a clue to explore the performance analysis for aero lubricating oils.

Figure 1 listed the total ion chromatogram of $\mathrm{EO}_{180^{-}}$ $\mathrm{EO}_{300}$ before $20.4 \mathrm{~min}$. As shown in Figure 1, in total, 50 compounds were detected with GC/MS, which included alkanes, alkenes, alcohols, acids, amines, ketones, monoesters, and diesters, and were displayed in Table 1. As demonstrated in Table 1, ester compounds dominated in detected compositions, which were 25 compounds. In addition, some chromogenic compounds are detected in $\mathrm{EO}_{180}-\mathrm{EO}_{300}$, including amines (peak 23, 25), phosphates (peak 30, 33, 42, 44-47), ketones (peak 12, 31, 36), and acids (peak 11, 43). Though few in content, they played a crucial role in significantly deepening color of aero lubricating oils. Meanwhile, these compounds, stronger in polarity, contributed to the enhancement of the acid number, increasing from $0.173 \mathrm{mg} \mathrm{KOH} / \mathrm{g}$ in $\mathrm{EO}_{180}$ to $10.450 \mathrm{mg} \mathrm{KOH} / \mathrm{g}$ in $\mathrm{EO}_{300}$.

3.2. The Deterioration Mechanism of Oils. Temperature is one of the most important factors for the deterioration of aero lubricating oil. As displayed in Figure 1 and Table 1, the product amounts were markedly increased with raising temperature and reached maxima at $300^{\circ} \mathrm{C}$ and properties of aero lubricating oil change with the oil's compositions. The deterioration of oils is generally considered tending to form free radicals and follow the chain reactions under high temperature and oxygen conditions. But little work has been published to date about the deterioration mechanism of aero lubricating oil. We focus our attention on possible reaction mechanism at the molecular level in order to slower or prevent oil deterioration. As shown in Scheme 1, possible chemical reactions are thermal pyrolysis, thermal oxidation, and thermal polymerization according to detected compounds in Table 1 .

3.2.1. Thermal Pyrolysis. DIOS, as based oil of experimental oil, is a long-chain diester with favorable symmetric structure with presented hydrogen of $\beta$-carbon at alcohol side. Hydrogen of $\beta$-carbon at alcohol side and oxygen of ester carbonyl groups formed intramolecular hydrogen bond by molecular movement, forming six-membered ring with $\mathrm{C}, \mathrm{O}$, and $\mathrm{H}$ atoms [13]. At high temperature, hexatomic ring was cracked into free radical I and II (Scheme 1(a)), and then free radical I and II recurred disproportionation reaction and generated 10-[(2-ethylhexyl)oxy]-10-oxodecanoate and 2-ethylhexene (peak 4, Scheme 1(b)). Along with the increase of reaction temperature, the relative abundances of 2-ethylhexene (peak 4) in $\mathrm{EO}_{180}$ to $\mathrm{EO}_{300}$ were 0.018, 0.012, 0.068, 0.293, 0.500 , and $5.213 \%$, respectively, indicating the pyrolysis extent of oil were significantly enhanced with raising temperature. 2-ethylhexene further produced ethylene and hexylene at the higher temperature (Scheme 1(c)). As 


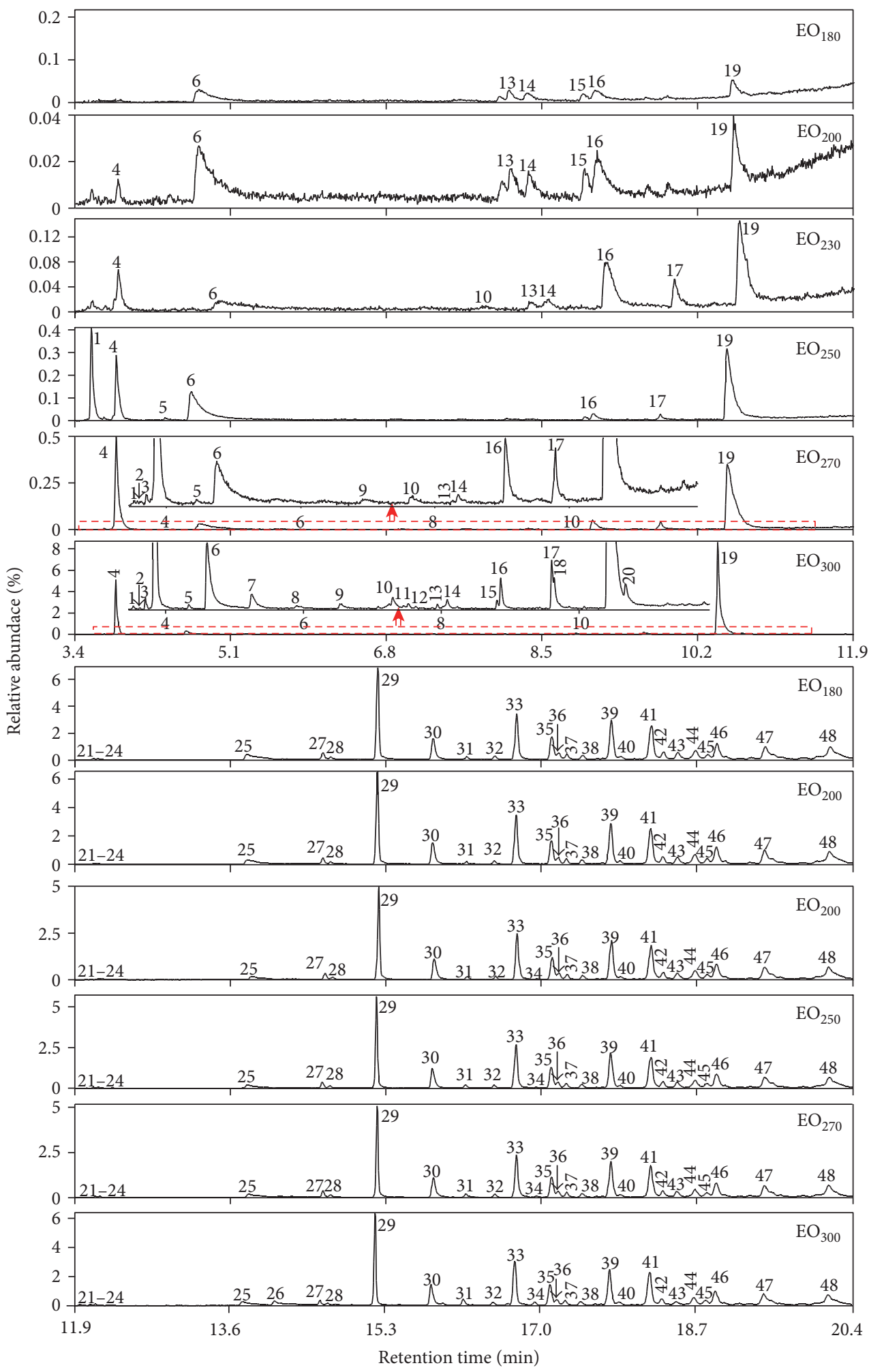

Figure 1: Total ion chromatograms of $\mathrm{EO}_{180}-\mathrm{EO}_{300}$ before $20.4 \mathrm{~min}$.

depicted in Scheme 1(d and e), parts of free radical II reacted with ethyl free radical and ethylene to generate 3-ethyloctane and 4-ethyloctene, respectively.

According to the structural formula, DIOS presented straight chain with eight carbons between ester groups. The straight chain could be cracked at high temperature, which is similar to straight-chain alkanes. The bonding energy of $\mathrm{C}-\mathrm{H}$ bond of alkanes was higher than that of the C-C bond; therefore, homolysis of thermal pyrolysis started with C-C bond [14, 15], so did DIOS. All C-C bonds between ester groups can cause homolytic reaction at high-temperature conditions. The generated free radicals 
TABLE 1: Distribution of compounds in $\mathrm{EO}_{180}-\mathrm{EO}_{300}$.

\begin{tabular}{|c|c|c|c|c|c|c|c|}
\hline Peak & Compound & $\mathrm{EO}_{180}$ & $\mathrm{EO}_{200}$ & $\mathrm{EO}_{230}$ & $\mathrm{EO}_{250}$ & $\mathrm{EO}_{270}$ & $\mathrm{EO}_{300}$ \\
\hline 1 & 2-Pentene & & & & $\times$ & $x$ & $x$ \\
\hline 2 & 4-Methyl-1-hexene & & & & & $x$ & $x$ \\
\hline 3 & 5-Methyl-3-heptene & & & & & $x$ & $x$ \\
\hline 4 & 3-Methylene & & $x$ & $x$ & $x$ & $x$ & $x$ \\
\hline 5 & 2-Ethylhexanal & & & & $x$ & $x$ & $x$ \\
\hline 6 & 2-Ethylhexane-1-alcohol & $x$ & $x$ & $x$ & $x$ & $x$ & $x$ \\
\hline 7 & 2-Ethylhexyl acetate & & & & & & $x$ \\
\hline 8 & 2-Ethylhexyl propionate & & & & & & $x$ \\
\hline 9 & 2-Ethylhexyl butyrate & & & & $x$ & $x$ & $x$ \\
\hline 10 & 2-Ethylhexyl valerate & & & $x$ & $x$ & $x$ & $x$ \\
\hline 11 & 12-Hydroxydodecanoic acid & & & & & & $x$ \\
\hline 12 & 4-Isopropylcyclohexane-1,3-diketone & & & & & & $x$ \\
\hline 13 & 2-Ethylhexyl-2-methoxyethyl acetate & $x$ & $x$ & $x$ & $x$ & $x$ & $x$ \\
\hline 14 & 2-Ethylhexylhexanoate & $x$ & $x$ & $x$ & $x$ & $x$ & $x$ \\
\hline 15 & 3-Ethylhexylhexanoate & $x$ & $x$ & $x$ & & & $x$ \\
\hline 16 & Unknown & $x$ & $x$ & $x$ & $x$ & $x$ & $x$ \\
\hline 17 & Unsaturated esters & & & $x$ & $x$ & $x$ & $x$ \\
\hline 18 & 2-Ethylhexyloctanoate & & & & & & $x$ \\
\hline 19 & Unknown & $x$ & $x$ & $x$ & $x$ & $x$ & $x$ \\
\hline 20 & 2-Ethylhexyldecanoate & & & & & & $x$ \\
\hline 21 & 2-Ethylhexylacryloyloate & $x$ & $x$ & $x$ & $x$ & $x$ & $x$ \\
\hline 22 & Unsaturated esters & $x$ & $x$ & $x$ & $x$ & $x$ & $x$ \\
\hline 23 & (E)-N-(4-Butoxybenzylidene)-4-ethylaniline & $x$ & $x$ & $x$ & $x$ & $x$ & $x$ \\
\hline 24 & Unknown & $x$ & $x$ & $x$ & $x$ & $x$ & $x$ \\
\hline 25 & N-Phenylnaphthalene-2-amine & $x$ & $x$ & $x$ & $x$ & $x$ & $x$ \\
\hline 26 & Unknown & & & & & & $x$ \\
\hline 27 & (E)-1-(Pentyloxy)-3-cinnamenylbenzene & $x$ & $x$ & $x$ & $x$ & $x$ & $x$ \\
\hline 28 & $\begin{array}{l}\text { 4-Methoxy-7-(2-methylbut-3-yn-2-oxy) } \\
\text { furano[2,3-b]quinoline }\end{array}$ & $x$ & $x$ & $x$ & $x$ & $x$ & $x$ \\
\hline 29 & Diisooctyl hexanedioate & $x$ & $x$ & $x$ & $x$ & $x$ & $x$ \\
\hline 30 & Triphenyl phosphate & $x$ & $x$ & $x$ & $x$ & $x$ & $x$ \\
\hline 31 & $\begin{array}{l}\text { 6-Heptyl-6-methyl-3-(pyridin-3-yl)-6,7-dihydro-1H- } \\
\text { indazole- } 4(5 \mathrm{H}) \text {-one }\end{array}$ & $x$ & $x$ & $x$ & $x$ & $x$ & $\times$ \\
\hline 32 & 6-(Benzyloxymethyl)-3-butyl-2,4-dihydroxybenzene(methane)al & $x$ & $x$ & $x$ & $x$ & $x$ & $x$ \\
\hline 33 & Diphenyl p-benzylphosphate & $x$ & $x$ & $x$ & $x$ & $x$ & $x$ \\
\hline 34 & Isomer of 36 & & & $x$ & $x$ & $x$ & $x$ \\
\hline 35 & Bis(2-ethylhexyl)decanedioate & $x$ & $x$ & $x$ & $x$ & $x$ & $x$ \\
\hline 36 & 1-(3'-Benzoyl-2,6-dimethoxybiphenyl-3-yl)ethanone & $x$ & $x$ & $x$ & $x$ & $x$ & $x$ \\
\hline 37 & Isomer of 36 & $x$ & $x$ & $x$ & $x$ & $x$ & $x$ \\
\hline 38 & Isomer of 36 & $x$ & $x$ & $x$ & $x$ & $x$ & $x$ \\
\hline 39 & Isomer of 36 & $x$ & $x$ & $x$ & $x$ & $x$ & $x$ \\
\hline 40 & Isomer of 36 & $x$ & $x$ & $x$ & $x$ & $x$ & $x$ \\
\hline 41 & Isomer of 36 & $x$ & $x$ & $x$ & $x$ & $x$ & $x$ \\
\hline 42 & Trio-benzylphosphate & $x$ & $x$ & $x$ & $x$ & $x$ & $x$ \\
\hline 43 & $\begin{array}{l}\text { 3-(5-(3-Hydroxy-4-methylphenyl)-1-(3-hydroxyphenyl)- } \\
\text { 1H-pyrrol-2-yl)propanoic acid }\end{array}$ & $x$ & $x$ & $x$ & $x$ & $x$ & $x$ \\
\hline 44 & Phenyldip-benzylphosphate & $x$ & $x$ & $x$ & $x$ & $x$ & $x$ \\
\hline 45 & 4-Ethylphenylphenyl p-benzylphosphate & $x$ & $x$ & $x$ & $x$ & $x$ & $x$ \\
\hline 46 & Isomer of 42 & $x$ & $x$ & $x$ & $x$ & $x$ & $x$ \\
\hline
\end{tabular}


TABLE 1: Continued.

\begin{tabular}{|c|c|c|c|c|c|c|c|}
\hline Peak & Compound & $\mathrm{EO}_{180}$ & $\mathrm{EO}_{200}$ & $\mathrm{EO}_{230}$ & $\mathrm{EO}_{250}$ & $\mathrm{EO}_{270}$ & $\mathrm{EO}_{300}$ \\
\hline 47 & Isomer of 42 & $\times$ & $\times$ & $\times$ & $\times$ & $\times$ & $\times$ \\
\hline 48 & Bis(2-ethylhexyl)decanedioate & $\times$ & $\times$ & $\times$ & $\times$ & $\times$ & $\times$ \\
\hline 49 & Isomer of 48 & $\times$ & $\times$ & $\times$ & $\times$ & $\times$ & $\times$ \\
\hline 50 & 1-(2-Ethyl-5-oxohexyl) 10-(2-ethylhexyl) decanedioate & $\times$ & $x$ & $\times$ & $x$ & $\times$ & $\times$ \\
\hline
\end{tabular}

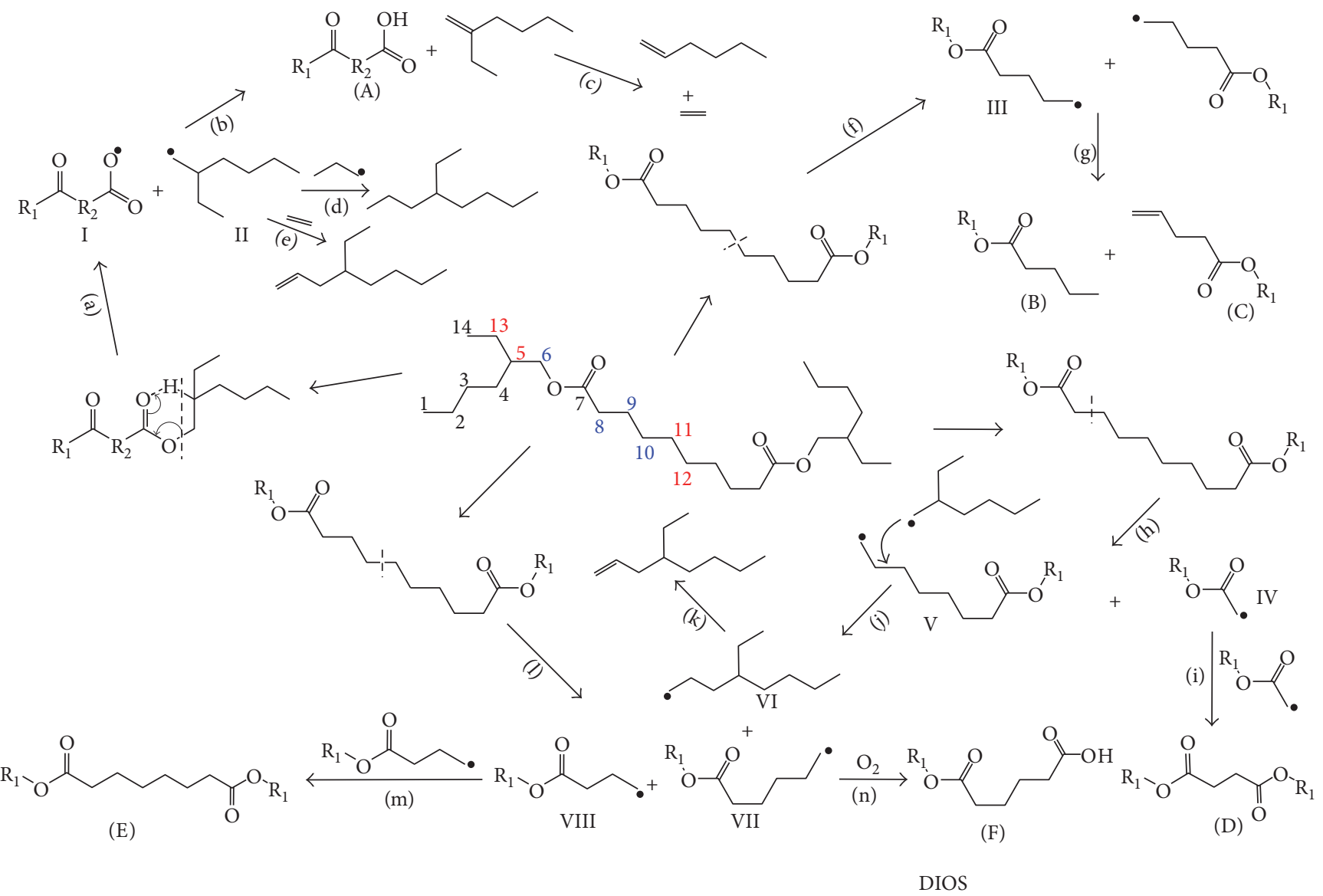

Scheme 1: Possible reaction process of thermal pyrolysis of DIOS.

caused disproportionation reaction to produce saturation and unsaturation monoester. The reaction processes and products of the cracked $\mathrm{C}-\mathrm{C}$ bond at different positions will be consequently discussed with the basis of GC/MS analysis.

As exhibited in Scheme 1, when the breakpoint is at the $\mathrm{C}_{11}-\mathrm{C}_{12}$ bond, DIOS could homolytically cracked two III free radicals (f). When two free radicals happened to have a collision, it will lead to the loss of Hand generated unsaturated 2-ethylhexyle-4-olefine acid monoester (C), whereas the other free radical generated saturated 2ethylhexyl-olefine acid monoester (B). When the breakpoint is at the $\mathrm{C}_{8}-\mathrm{C}_{9}$ bond, DIOS generated IV and V free radicals and then two IV free radicals can generate low molecular weight di-2-ethylhexyl diester by coupling reaction (D). In this system, II free radical attacked the $\beta$-carbon of $\mathrm{V}$ free radical to generate VII free radical and alkyl radical with molecular weight of 141, whereas alkyl radical lost $\mathrm{H}$ atom and formed the alkene with molecular weight of 140 (Scheme $1(\mathrm{j}$ and $\mathrm{k})$ ). When point of fracture is at the $\mathrm{C}_{10}-\mathrm{C}_{11}$ bond, DIOS generated two VII and VIII free radicals, and two VIII free radicals bumped together and formed caprylyl glycol adipate (E) by coupling reaction (Scheme 1(m)). VIII free radical was oxidized by oxygen at some temperature and formed the 6-(2-ethylhexyloxy)-6diakyl hexylic acid (Scheme 1(n)). When the breakpoint is at the $\mathrm{C}_{9}-\mathrm{C}_{10}$ bond, DIOS could generate two free radicals and then formed diisooctyl adipate (F) by coupling reaction. Table 2 displayed the part ester compounds of $\mathrm{EO}_{300}$.

Spatial position and the near groups varied with the type of the $\mathrm{C}-\mathrm{C}$ bond, resulting in different interactions involved. Therefore, the hemolytic cleavage of the different $\mathrm{C}-\mathrm{C}$ bonds 
TABLE 2: Several ester compounds of $\mathrm{EO}_{300}$.

Peak

7

9

10

14

15

18

20

29

35
Compound

2-Ethylhexylacetate

2-Ethylhexylpropanoate

2-Ethylhexylbutanoate

2-Ethylhexylvalerate

2-Ethylhexylhexanoate

3-Ethylhexylhexanoate

2-Ethylhexyloctanoate

2-Ethylhexyldecanoate

Diisooctyl hexanedioate

Diisooctyl decanedioate
Structural formula<smiles>CCCCC(CC)COC(C)=O</smiles><smiles>CCCCC(CC)COC(=O)CC</smiles><smiles>CCCCC(CC)COC(=O)CCC</smiles><smiles>CCCCC(=O)OCC(CC)CCCC</smiles><smiles>CCCCCC(=O)OCC(CC)CCCC</smiles><smiles>CCCCCC(=O)OCCC(CC)CCC</smiles>
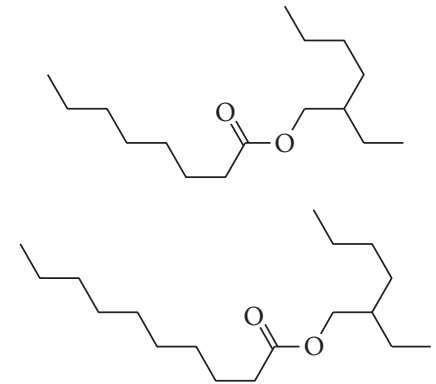<smiles>CCCCC(CC)COC(=O)CCCCC(=O)OCC(CC)CCCC</smiles>

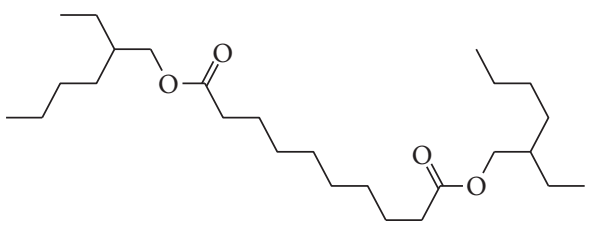


at high temperatures leads to the different abilities of free radicals. Generally, bond length of chemical bond is inversely proportional to the bond energy: the more low bond energies, the more crack of chemical bond. Zhou et al. [16] calculated the bonding energies of C-C bond of $n$-decane and xylene by computational chemistry method. The results indicated that the low bonding energy of $n$-decane can more easily cause thermal pyrolysis.

The structure of DIOS was optimized by using semiempirical method (PM3 method) with an aid of Hyperchem 7.0 software (Figure 2). Table 3 exhibited the bond length of various $\mathrm{C}-\mathrm{C}$ bonds between ester groups. The fitted results of HyperChem indicated that the bonding length of the $\mathrm{C}_{7}-\mathrm{C}_{8}$ bond was significantly lower than that of other $\mathrm{C}-\mathrm{C}$ bonds, revealing that $\mathrm{C}_{7}-\mathrm{C}_{8}$ bond was not easy to break. The difference in bond length of other four $\mathrm{C}-\mathrm{C}$ bonds suggested that the $\mathrm{C}-\mathrm{C}$ bond could be broken at high temperature, which was consistent with the deterioration mechanism of DIOS as based oil. Thermal pyrolysis included the cracking of six-membered ring and long carbon chain between ester groups. The cracking of long carbon chain between ester groups at different positions formed the different free radicals [17]. The collision of free radicals caused coupling and disproportionation reaction, resulting in formation of unsaturation and saturation monoesters, diesters with molecular weight less than DIOS, and part diesters with molecular weight more than DIOS.

3.2.2. Thermal Oxidization. Besides thermal pyrolysis, DIOS can cause thermal oxidization by the effect of oxygen under metal catalysis and high-temperature conditions. Alkene and reactive free radicals derived from thermal pyrolysis could be oxidized to form acid oxygen-containing compounds (peaks 11, 12, 31, 36, and 43), which lead to increasing acid number. Table 4 listed the acid number of experimental oils under different temperatures. As shown in Table 4, the acid number of $\mathrm{EO}_{180}$ is $0.173 \mathrm{mg}$ $\mathrm{KOH} / \mathrm{g}$, which was lower than critical value $(0.5 \mathrm{mg}$ $\mathrm{KOH} / \mathrm{g}$ ) with less corrosion for engine. However, the acid number was $1.011 \mathrm{mg} \mathrm{KOH} / \mathrm{g}$ at $250^{\circ} \mathrm{C}$, which could mildly lead to the corrosion of the engine. Furthermore, when the heated temperature increases to $300^{\circ} \mathrm{C}$, the acid number dramatically reached to $10.450 \mathrm{mg} \mathrm{KOH} / \mathrm{g}$, which meant that the engine was corroded severely and the aero lubricating oil must be replaced.

3.2.3. Thermal Polymerization. The deterioration process not only is the cleavage of bonds but also includes polymerization, especially polycondensation at high temperature. It was reported that the oxidation products of lubricating oil could be condensed to polyoxides and then further formed the macromolecules [18, 19]. As expected from the GC/MS results, compounds of high molecular weight were detected in total ion chromatograms after $20.4 \mathrm{~min}$. Due to the disadvantage of GC/MS, which only detects compounds with a molecular weight of less than 500 , compounds of high molecular weight could not be detected and identified. Therefore, further research will

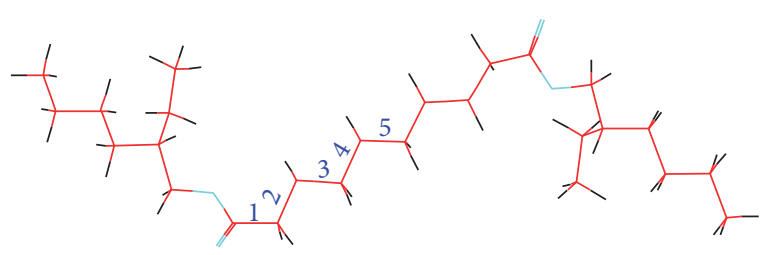

Figure 2: Optimized structure of DIOS.

TABLe 3: Simulated results of bond length by HyperChem.

\begin{tabular}{lccccc}
\hline Number & 1 & 2 & 3 & 4 & 5 \\
\hline Bond length & 1.5134 & 1.5209 & 1.5213 & 1.5202 & 1.5207 \\
\hline
\end{tabular}

TABle 4: Acid number (mg KOH/g) of $\mathrm{EO}_{180}-\mathrm{EO}_{300}$.

\begin{tabular}{lccc}
\hline Sample & Acid number & Sample & Acid number \\
\hline $\mathrm{EO}_{180}$ & 0.173 & $\mathrm{EO}_{250}$ & 1.011 \\
$\mathrm{EO}_{200}$ & 0.221 & $\mathrm{EO}_{270}$ & 2.092 \\
$\mathrm{EO}_{230}$ & 0.728 & $\mathrm{EO}_{300}$ & 10.450 \\
\hline
\end{tabular}

focus on identifying the macromolecules from oils. These macromolecules, which combined with degraded products of additives and wear metallic particles, formed oil sludge. Oil sludge could be dissolved into oils and/or deposited to the surface of engine or blocked the strainer and gallery, which decreased lubrication effect due to lack of oil supply.

\section{Conclusions}

In summary, it is demonstrated that some aero lubricating oil significantly cause deterioration with air under high temperature. According to analysis with GC/MS, three reactions were presented, which mainly included thermal pyrolysis, thermal oxidation, and thermal polymerization, and thermal pyrolysis dominated at high temperature. Thermal pyrolysis included the pyrolysis of six-ring esters and pyrolysis of long carbon chain of ester groups, resulting in formation of acid, alkene, and various reactive intermediates. And thermal reactions between alkene/reactive intermediates and oxygen generated chromogenic compounds, such as alcohol, aldehyde, and acid. In addition, coupling and disproportionation reactions were observed by collision of free radicals, which generated unsaturated monoester, saturated monoester, diesters, and high-molecular-height polymers. The thermal pyrolysis of DIOS generated acid substances, and derivative of part additives resulted in the increase of acid number of oil products. Moreover, these products influenced the aero lubricating oil properties. The products of thermal oxidation were ester- and hydrocarbon-like compounds. The former and the latter were the chromophoric and auxochromous substance, respectively, which lead to the dark 
color of oil products after the oxidation process. The thermal polymerization generated the large molecular weight ester compounds. Then these ester compounds and degradation products generated oil sludge. The overabundance of oil sludge will block oil line and decreased the lubrication effect afterwards.

\section{Conflicts of Interest}

The authors declare that they have no conflicts of interest.

\section{Acknowledgments}

Financial supports from the Project of Youth Fund of Jiangsu Province (no. BK20150166), Scientific Researching Youth Fund Projects of Air Force Logistics College (no. 2016xkjq006), Natural Science Foundation of the Anhui Higher Education Institutions of China (no. KJ2017A400), and National Natural Science Fund of China (no. 51575525) were acknowledged.

\section{References}

[1] D. C. Kramer, J. N. Ziemer, and M. T. Cheng, "Influence of group II \& III base oil composition on VI and oxidation stability," Nlgi Spokesman, vol. 63, no. 10, pp. 20-39, 2000.

[2] H. Nakanishi, K. Onodera, K. Inoue, Y. Yamada, and M. Hirata, "Oxidation stability of synthetic lubricants," Lubrication Engineers, vol. 53, no. 5, pp. 29-37, 1997.

[3] L. N. Edmund, "Neopentyl polyol ester lubricants-bulk property optimization," Industrial \& Engineering Chemistry Product Research and Development, vol. 15, no. 1, pp. 54-58, 1976.

[4] W. Liu, J. Xu, and D. Feng, "Research status and development tendency of synthetic lubricating oil," Tribology, vol. 33, no. 1, pp. 91-104, 2013, (In Chinese).

[5] X. Fan, J. Jiang, L. Chen et al., "Identification of organic fluorides and distribution of organic species in an anthracite with high content of fluorine," Fuel Processing Technology, vol. 142, pp. 54-58, 2016.

[6] K. C. Jayaprakash, S. P. Srivastava, K. S. Anand, and P. K. Goel, "Oxidation stability of steam turbine oils and laboratory methods of evaluation," Lubrication Engineers, vol. 40, no. 2, pp. 89-95, 1984.

[7] A. C. M. Wilson, "Problems encountered with turbine lubricants and associated systems," Lubrication Engineers, vol. 32, no. 2, pp. 59-65, 1976.

[8] L. B. Chen, S. H. Guo, S. Y. Li, L. Q. Song, and Z. G. Zhang, "Thermal oxidization kinetics of antioxidant in aero lubricating oil," Journal of Fuel Chemistry and Technology, vol. 30, no. 6, pp. 523-528, 2002, (In Chinese).

[9] Y. W. Fei, X. L. Peng, T. Yao, F. Guo, and Y. H. Wang, "Component analysis of ester-like aero lubricating oil at high temperature," Petrochemical Technology, vol. 43, no. 12, pp. 1444-1449, 2014, (In Chinese).

[10] Y. Wu, W. Li, and X. Wang, "The influence of oxidation on the tribological performance of diester lubricant," Lubrication Science, vol. 26, no. 1, pp. 55-65, 2013.

[11] J. C. O. Santos, I. M. G. Santos, and A. Souza, "Thermal degradation process of synthetic lubricating oils: part I, spectroscopic study," Petroleum Science and Technology, vol. 33, no. 11, pp. 1238-1245, 2015.
[12] Y. W. Fei, Z. S. Cheng, H. W. Yang, and T. Yao, "Characteristic analysis of ester-like synthetic aero lubricating carrier oil," Contemportary Chemical Industry, vol. 42, no. 9, pp. 12971300, 2014, (In Chinese).

[13] N. Ponnekanti and K. Savita, "Study of synthetic complex esters as automotive gear lubricants," Journal of Synthetic Lubrication, vol. 25, no. 25, pp. 131-136, 2008.

[14] F. C. Li, J. S. Zhang, and Q. M. Yuan, "Reaction mechanism of thermal and catalytic pyrolysis of octane and formation of methane," Journal of Fuel Chemistry and Technology, vol. 42, no. 6, pp. 697-703, 2014, (In Chinese).

[15] B. Y. Wang, N. X. Tan, Q. Yao, and Z. R. Li, “Accurate calculation of the reaction barriers and rate constants of the pyrolysis of alkyl radicals in the $\beta$-position using the isodesmic reaction method," Acta Physico-Chimica Sinica, vol. 28, no. 12, pp. 2824-2830, 2012, (In Chinese).

[16] H. Zhou, J. Mao, B. Y. Wang, Q. Zhu, J. L. Wang, and X. Y. Li, "Thermal pyrolysis of decane and xylene under supercritical pressure conditions," Acta Physico-Chimica Sinica, vol. 29, no. 4, pp. 689-694, 2013, (In Chinese).

[17] M. Wang, X. Fan, X. Y. Wei et al., "Characterization of the oxidation products of Shengli lignite using mass spectrometers with 'hard', 'soft' and ambient ion sources," Fuel, vol. 183, pp. 115-122, 2016.

[18] J. F. Lahijani, F. E. Lockwood, and E. E. Klaus, "The influence of metals on sludge formation," A S L E Transactions, vol. 25, no. 1, pp. 25-32, 1982.

[19] J. A. Supp and R. E. Kornbrekke, "Deposit formation in gasoline engines: part 1. Base oil in sequence VE deposits," Lubrication Engineers, vol. 50, no. 12, pp. 964-969, 1994. 

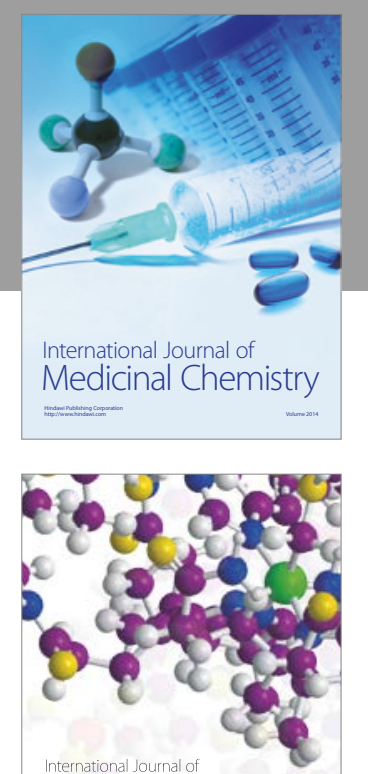

Carbohydrate Chemistry

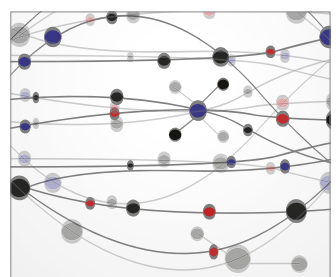

The Scientific World Journal
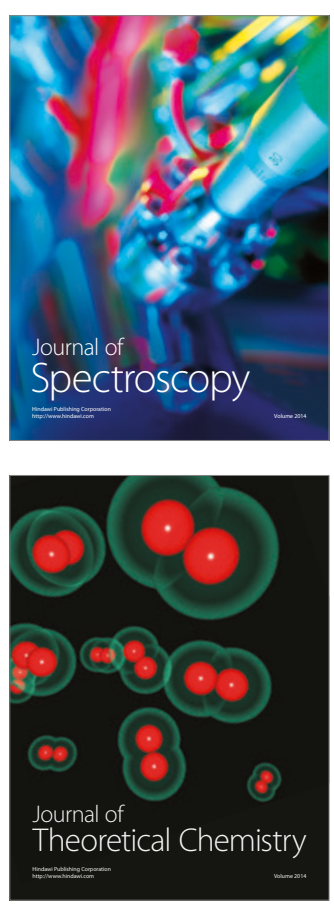
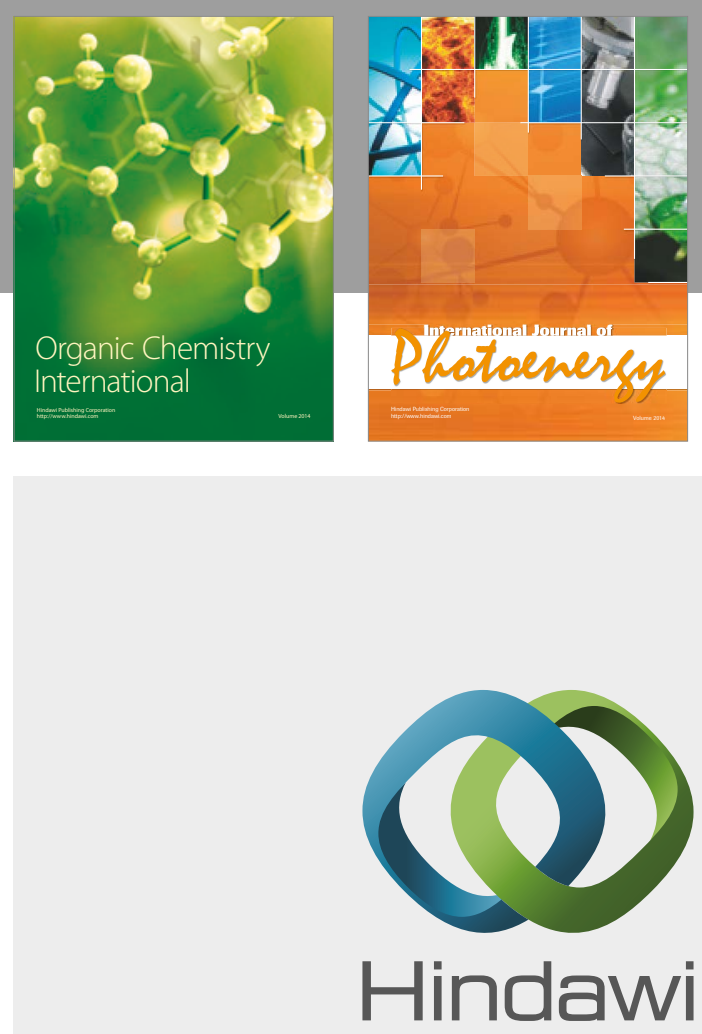

Submit your manuscripts at

https://www.hindawi.com

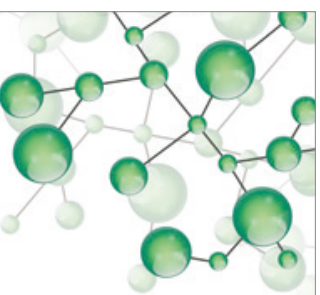

International Journal of

Inorganic Chemistry

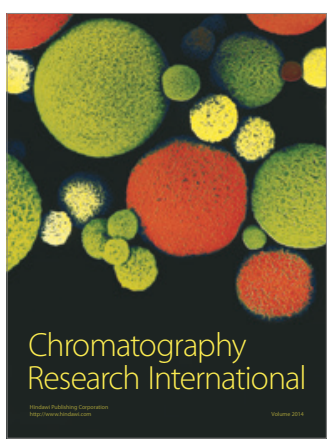

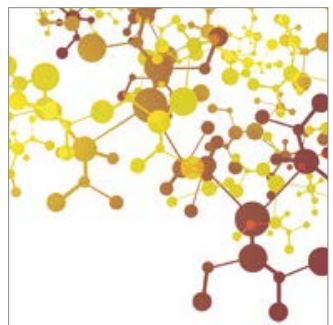

Applied Chemistry
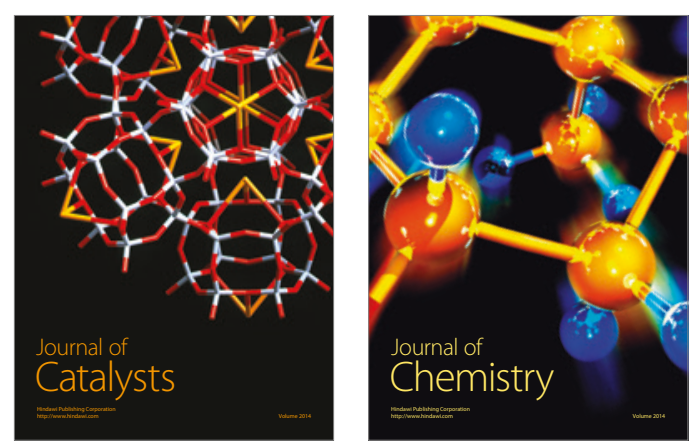
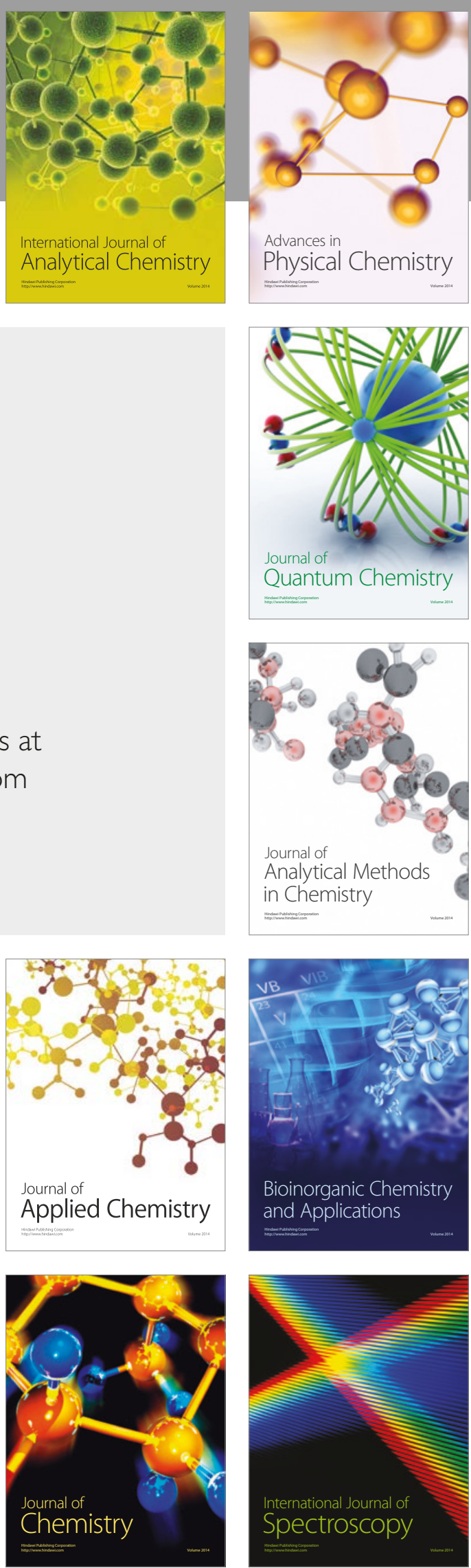